\title{
Labor Regulation and Unemployment: The Case of Tunisia
}

\author{
Salah Ahmed ${ }^{1}$, Ali Aljane ${ }^{2}$
}

\begin{abstract}
:
Using a different database of labor regulation, we sketch the relationship between labor market flexibility and unemployment in Tunisia during the period 2000-2013. The results of the study find no link between labor regulation and unemployment. The main finding from the dynamic panel estimation is that the labor regulation composite indicator used does not have a statistically significant association with the unemployment rate for the selected 115 developing countries. However, there is a direct link between the firing and hiring regulation and unemployment. In addition, the interactive variable between these indicators and the dummy variable for Tunisia doesn't seem to explain why unemployment is higher in Tunisia than in other countries. Regulation has no adverse effect on aggregate unemployment.
\end{abstract}

Key Words: Labor market; flexibility, unemployment

JEL Classification: E29; J60; E32; D7

\footnotetext{
${ }^{1}$ Université de Tunis El Manar, Faculté des Sciences Economiques et de Gestion de Tunis, 2092, Tunis, Tunisie; ahmedtun7@yahoo.fr

2 Université de Tunis El Manar, Faculté des Sciences Economiques et de Gestion de Tunis, Prospective, Stratégies et Développement Durable (PS2D), 2092, Tunis, Tunisie, aaljane@gnet.tn
} 


\section{Introduction}

Unemployment rate in Tunisia is among the highest in the world and is largely an issue of youth. Tunisia's unemployment rate is currently between $15 \%$ and $18 \%$ and it is above MENA's average unemployment rate by about $3 \%$ to $4 \%$ in $2000-2010$ and $8 \%$ in 2011.

Though, Tunisia's annual growth rate of GDP was relatively high during the two last decades ( $4 \%$ to $5 \%$ ), it did little to drop the unemployment rate which remained at its high levels.

Moreover, the recent social and political events in Tunisia have contributed to the decline of economic activity and to the increase of unemployment. For instance, in the early 2011, unemployment has increased by about $7 \%$.

While some changes in the unemployment rate have been related to the business cycle, structural unemployment remains a major component. The latter is related to the labor market institutions.

In the literature, the relationship between labor market institutions and unemployment remains widely debated and there is no consensus among economists on the impact of institutions on labor market outcomes.

The orthodox view as represented by the OECD (1994) has been challenged by recent research (Bassanini and Duval 2006; Baker et al. 2005 ...). Indeed, much of the literature agrees that Employment Protection Legislation (EPL) has an adverse effect on unemployment.

Botero et al. (2004), Djankov Simeon and Rita Ramalho (2009) find that the more rigid the employment laws are, the high are the rates of unemployment; especially for the young people.

In a cross-national study of labor market regulations in 73 developed and developing countries, Feldman (2009) highlights the fact that strict labor market regulations increases unemployment all over the world. Likewise, Bernal-Verdugo et al. (2012) argue that increased labor market flexibility can have an important effect in reducing unemployment.

It is worthy to note that most of the previous studies are conducted for developed countries and a very little attention has been given to the developing countries. Therefore, this study is an attempt to fill this gap in the context of Tunisia. Our aim is to examine the effects of the EPL on aggregate and youth unemployment in the developing countries and more particularly in Tunisia. 
The paper is organized as follow: in section 2 we present the characteristics of the labor market regulation in Tunisia in a comparative perspective. Section 3 describes the methodology used to test the effects of the labor law regulation on unemployment, following that we provide the different results. Finally, and in a fourth section, we discuss the main findings and conclude.

\section{The labor market regulation in Tunisia}

In Tunisia, the regulation of the labor market includes many measures intended to protect the employment sector. The intervention of the State in the labor market is traditionally important. In the wage bargaining, the tripartite mechanism ${ }^{3}$ has played an important role in the organization of the labor market, particularly in promoting measures for the reintegration of the manpower, fixing of salaries and to limit the shocks caused by the macroeconomic changes.

Revision of the Labor Code (adopted in 1966) conducted in 1994 and 1996 aims the relaxation of the rules of work at the levels of the hiring and at the dismissal. The Labor Code has allowed a degree of flexibility by the introduction of the fixed-term contracts.

Dismissals for economic reasons are not allowed, while procedural inconveniences for employers to dismiss redundant workers are extremely costly.

Only one out of seven cases of dismissals ends up being accepted, and employers perceive that dismissal processes have a de facto bias toward workers. As a result, annual layoffs are less than 1 percent of the workforce compared to more than 10 percent in the average OECD country.

According to the Global Competitiveness Report 2011-2012, hiring and firing regulations in Tunisia are more restrictive than those in the average emerging and developing country.

Similarly, data from enterprise surveys indicates that, worldwide, the percentage of firms identifying labor regulation as a major constraint to their business operations is, on average, greatest in Tunisia.

In addition, indicators of labor market flexibility show that such rigidities are particularly high and could significantly limit employment creation, particularly for first-time job seekers, by discouraging firms from expanding employment in response to favorable changes in the economic climate.

In this study, we retain database from The Fraser Institute's Economic Freedom of the World, which provides a composite measure of labor market flexibility.

\footnotetext{
${ }^{3}$ Mechanism that involves the Government, the workers and the employers unions.
} 
From 2001, the Institute Fraser on Economic Freedom in the World (EFW) gives six sub-indicators of labor institutions as a part of its indicator of economic freedom market. The composite indicator is standardized on a 0-10 range, with higher value of the indicator representing a more flexible labor market. This measure gives a lower rating to countries in which the free hiring and firing of workers is impeded by regulation.

These sub-indicators are:

i) Hiring regulations and minimum wage

ii) Hiring and Firing regulations

iii) Centralized collective bargaining assigns ratings based on the centralization of the wage bargaining process, which are higher for countries with a more decentralized bargaining process;

iv) The index of mandated cost of worker dismissal rates countries based on the cost of the requirements for advance notice, severance payments, and penalties due when dismissing a redundant worker;

v) The index of conscription rates countries based on the use and duration of military conscription, with the highest rating given to countries without military conscription.

The use of indices developed from subjective data raises many reserves (Berg Janine and Sandrine Cazes, 2007). This indicator contains several conceptual problems, including the simplistic idea according to which "the regulation is a cost", which ignores the positive externalities associated with the right of the work and who is really the reason to be. It ignores many of the rights listed in the standards of the ILO and the international labor Conventions and has a tendency to discourage countries to meet a large number of international labor conventions of the ILO.

In focusing on the external numerical flexibility, it neglects other important means of adjustment of the labor market, such as the flexibility of wages or that of the functions.

This indicator points out that Tunisia labor market is overall not so rigid in absolute terms (scoring 6 out of 10), but less flexible than in other emerging countries.

In addition, it seems that some sub- indices of labor market regulation are less than in other emerging countries. These are the cases of the hiring regulations and minimum wage, the hiring and firing regulations and the centralized collective bargaining. 
Graph 1. Indicators of deregulation in the Arab countries in 2010

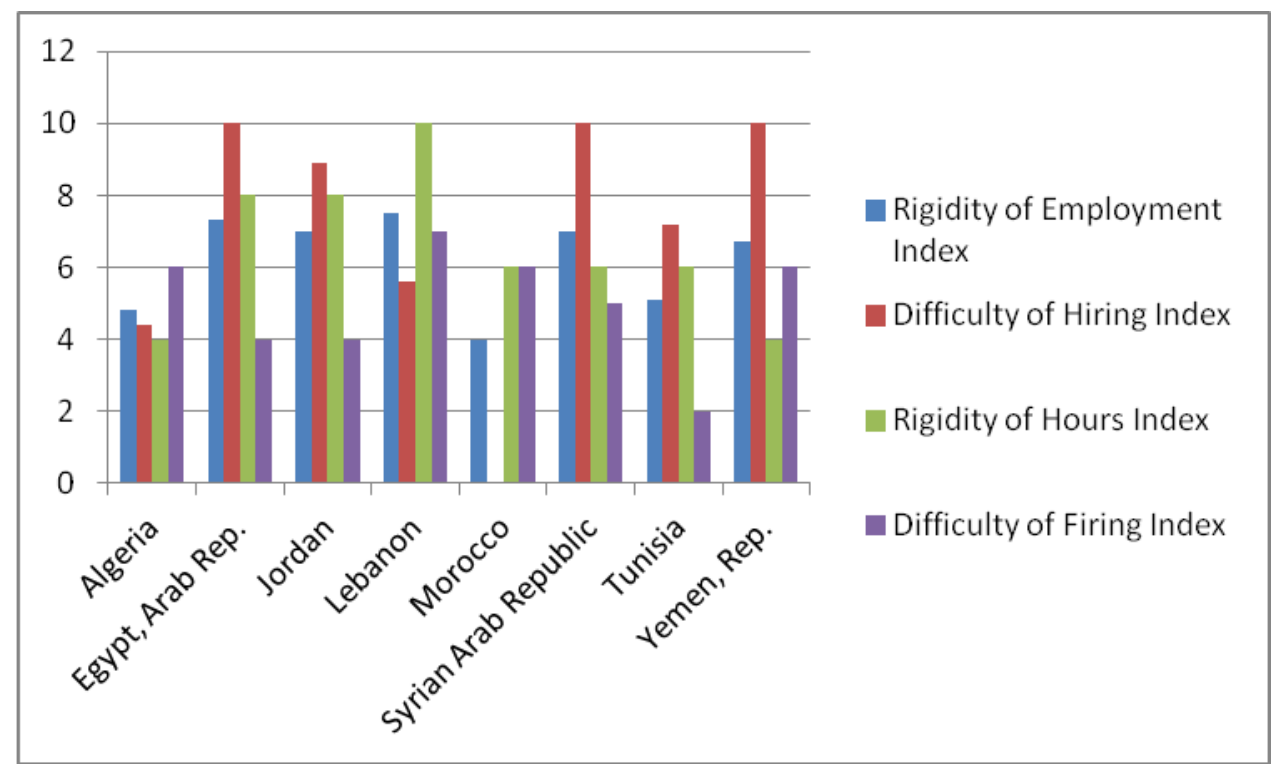

Source: Fraser Institute's Economic Freedom of the World (EFW) database

Graph 2. Indicators of in deregulation in 2010

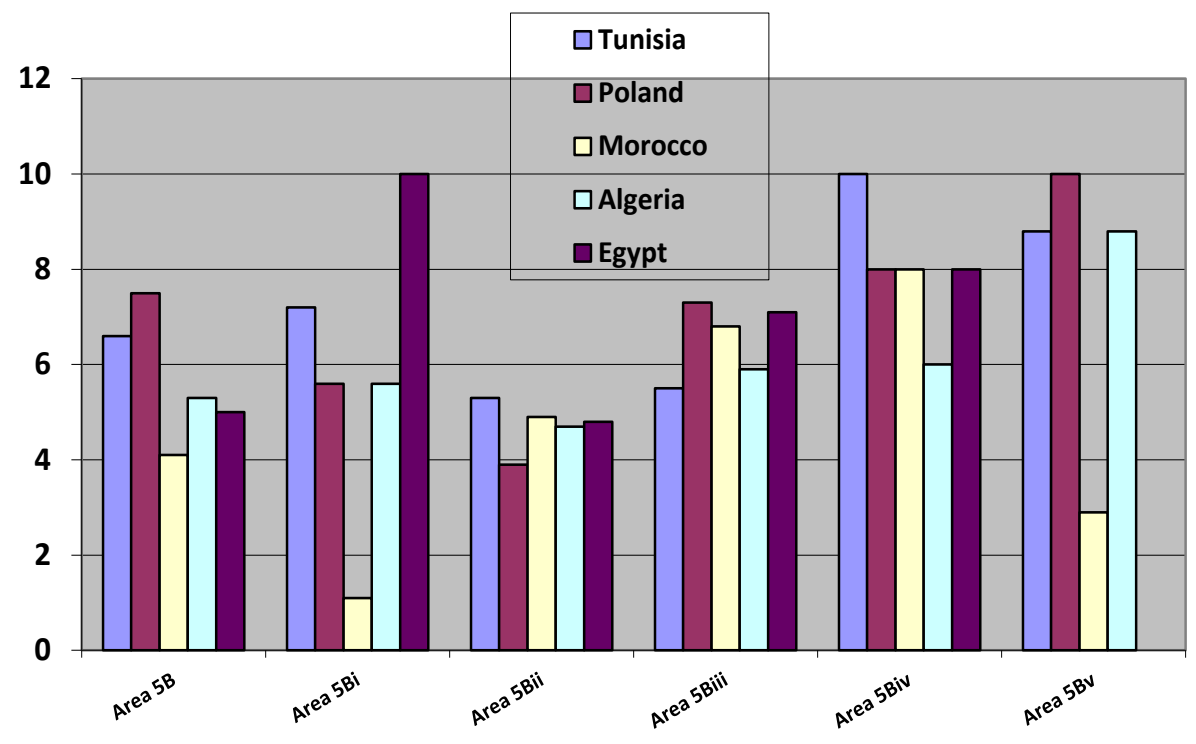




\section{Methodology and Results}

In order to test the impact of the regulation of the labor market on the evolution of unemployment, we have retained a modified version of the model of Blanchard and wolfers (2000):

- In a static framework, the model can be written as follow:

$u_{i t}=\alpha_{i}+\beta L_{i t}+\delta L_{i t} D+\sum \gamma_{j} X_{j i t}+\varepsilon_{i t}$

$u_{i t}$ is the unemployment rate at time $t$ in country $\mathrm{i}$

$\alpha_{i}$ is a specific effect to each country; it represents country dummies that capture unobserved country-specific determinants of unemployment.

$\mathrm{L}$ is a vector of institutional indicators of the labor market.

$\mathrm{D}$ a dummy variable that takes value equal to 1 for Tunisia and zero otherwise.

$\mathrm{X} \mathrm{j}$ is a set of macro-economic variables (growth of productivity, the real interest rate, and inflation);

$\varepsilon \mathrm{i}, \mathrm{t}$ is an error term.

The subscripts $\mathrm{i}$ and $\mathrm{t}$ represent the particular country and the year, the superscript $\mathrm{j}$ stands for the particular independent variable

- In a dynamic framework, the model is as follow:

$u_{i t}=\alpha_{i}+\rho u_{i t-1}+\beta L_{i t}+\delta L_{i t} D+\sum \gamma_{j} X_{j i t}+\varepsilon_{i t}$

Several econometric problems may arise from estimating the above equation.

The endogeneity which is due to the presence of the lagged level of unemployment among the regressors and to reverse causality from changes in unemployment to labor market flexibility,

The presence of the lagged dependent variable $u_{i t-1}$ gives rise to autocorrelation.

Time-invariant country characteristics (fixed effects), such as geography and demographics, may be correlated with the explanatory variables. The fixed effects are contained in the error term in equation (2), which consists of the unobserved country-specific effects, vi, and the observation-specific errors, eit

The coefficients on the lagged levels of independent variables provide an estimate of the long-term (permanent) effect of change in these variables on unemployment.

$$
\Delta u_{i t}=\alpha_{i}+\rho u_{i t-1}+\beta L_{i t}+\delta L_{i t} D+\sum \gamma_{j} X_{j i t}+\varepsilon_{i t}
$$

While $\Delta$ is the first-difference estimator, the lagged dependent variable is included among the predictors to capture the persistence of unemployment and hysteresis effects (Nickell et al. 2005).

Changes in the unemployment rate also can cause policy makers to change employment protection legislations to address the adverse developments in the labor 
market, and therefore, unemployment rate. In such cases, the direction of causality from the unemployment rate to employment protection legislations creates an endogeneity problem in regression estimations. Equation 3 is estimated using the two-step GMM-system estimator.

All explanatory variables are considered as endogenous (instrumented using up to 2 lags). The significance of the results is robust to different choices of instruments and predetermined variables.

The objective of the estimate is to test why Tunisia has a higher unemployment rate than the average of other comparable countries, such as those of the Arab region and the countries in transition.

Suppose that the model is validated for the sample considered, we are trying to explain the differential of the unemployment rate in Tunisia compared to the other countries by differences in the determinants as well as by the initial unemployment rate.

The macroeconomic controls include GDP growth, the change in inflation (CPI), the terms of trade and the real interest rate. GDP growth and the change in inflation capture the influence of economic cycles. A fall in output is expected to be associated with higher unemployment. Following the logic of the Phillips curve, the change in inflation should be negatively related to unemployment in the short run. The terms of trade should have a negative relationship with unemployment. A deterioration of the terms of trade requires a downward adjustment of real wages. If wages do not respond accordingly, unemployment will likely increase. Finally, the real interest rate affects capital accumulation and can cause shifts in labor demand. This variable should increase unemployment because an increase in real interest rates is likely to reduce aggregate demand (Baker et al. 2005). Models of youth unemployment also include the ratio of youth to adult (25-54 years) population as an additional control.

The sample consists of 115 developing countries and covers the period 2000-2013.

Given the dynamic nature of these models, the potential concerns about the Nickell bias endogeneity problems may still be present if omitted variables influence simultaneously EPL and unemployment. The Nickell bias (1981) refers to situations in which the inclusion of the lagged dependent variable makes the fixed-effect estimator biased due to the correlation between the demeaned lagged dependent variable and the error term.

Since this estimator is designed for small $\mathrm{T}$ panels, difference GMM models (Arellano and Bond 1991), where institutional variables dated $\mathrm{t}-2$ and earlier are used as instruments. 
Table 1. Unemployment and Labor Market Flexibility-Dynamic Regression (GMM)

\begin{tabular}{|c|c|c|c|c|c|}
\hline $\begin{array}{l}\text { Dependant } \\
\text { variable : } \\
\text { D.unemp }\end{array}$ & (1) & (2) & (3) & (4) & (5) \\
\hline Unemp(t-1) & $\begin{array}{l}-0.203 * * * \\
(-3.59)\end{array}$ & $\begin{array}{l}-0.243^{* *} \\
(-3.16)\end{array}$ & $\begin{array}{l}-0.251 * * * \\
(-3.90)\end{array}$ & $\begin{array}{l}-0.176^{* *} \\
(-3.27)\end{array}$ & $\begin{array}{l}-0.192 * * \\
(-3.07)\end{array}$ \\
\hline Laboreg & $\begin{array}{l}0.0638 \\
(0.60)\end{array}$ & $\begin{array}{l}-0.00357 \\
(-0.02)\end{array}$ & & & \\
\hline imf_inflch & $\begin{array}{l}-0.00544 \\
(-1.92)\end{array}$ & & & & \\
\hline D* laboreg & $\begin{array}{l}-0.721 \\
(-0.49)\end{array}$ & $\begin{array}{l}0.969 \\
(0.56)\end{array}$ & & & \\
\hline imf_gdpgr & $\begin{array}{l} \\
0.0944 * * \\
* \\
(-4.52)\end{array}$ & $\begin{array}{l} \\
0.0859 * * \\
* \\
(-3.41)\end{array}$ & $\begin{array}{l}- \\
0.0917 * * \\
* \\
(-3.33)\end{array}$ & $\begin{array}{l}- \\
0.0890 * * \\
* \\
(-3.37)\end{array}$ & $\begin{array}{l}- \\
0.0944 * * \\
* \\
(-3.40)\end{array}$ \\
\hline Hiring and firing & & & $\begin{array}{l}-0.470^{*} \\
(-2.50)\end{array}$ & & $\begin{array}{l}-0.259 \\
(-1.60)\end{array}$ \\
\hline $\mathrm{D}^{*}$ hiringfiringreg & & & $\begin{array}{l}1.068 \\
(1.26)\end{array}$ & & $\begin{array}{l}0.564 \\
(0.75)\end{array}$ \\
\hline centcolbargaining & & & & $\begin{array}{l}-0.117 \\
(-0.52)\end{array}$ & \\
\hline $\begin{array}{l}\text { D*centcolbargainin } \\
\mathrm{g}\end{array}$ & & & & $\begin{array}{l}0.241 \\
(0.22)\end{array}$ & \\
\hline Constant & $\begin{array}{l}1.764^{*} \\
(2.06)\end{array}$ & $\begin{array}{l}2.326 \\
(1.45)\end{array}$ & $\begin{array}{l}4.636^{* * * *} \\
(3.73)\end{array}$ & $\begin{array}{l}2.491 \\
(1.70)\end{array}$ & $\begin{array}{l}3.094 * * \\
(2.85)\end{array}$ \\
\hline Observations & 1184 & 1184 & 1062 & 1062 & 1062 \\
\hline Number of coutries & 115 & 115 & 108 & 108 & 108 \\
\hline Hansentest, p-value & 0.471 & 0.432 & 0.336 & 0.516 & 0.418 \\
\hline $\mathrm{AR}(2)$ test, $\mathrm{p}$-value & 0.679 & 0.653 & 0.628 & 0.608 & 0.630 \\
\hline Instrum. No & 52 & 39 & 39 & 51 & 51 \\
\hline
\end{tabular}

Note $: \mathrm{t}-$ statistics in parenthesis $* \mathrm{p}<0.05,{ }^{* *} \mathrm{p}<0.01, * * * \mathrm{p}<0.001$

Table 1 presents the results after using the model GMM system. The results obtained suggest that the effect of the flexibility of the labor market is not statistically significant with the exception of the flexibility of the Hiring and firing regulation. 
The coefficients associated with the interactive variables constructed for Tunisia and indicating the flexibility of its labor market are not statistically significant, which suggests that the improvement in labor market flexibility does not affect the unemployment rate, even over the medium term.

Our results are in conformity with of the recent studies of Avdagic and Salardi (2013) and Deakin and Prabirjit (2015).

\section{Conclusions}

The analysis of the results of the estimations highlights the following conclusions:

In spite of the flexibility of the labor market by the introduction of temporary work contracts, the unemployment remains high in Tunisia.

The effects of labor market institutions are more complex than do the neoliberal approach according to which the stringent labor protection increases unemployment.

The complexity of the relationship between regulation and employment stems from the fact that the labor institutions are part of social standards which are specific to each country.

The structural reforms aiming to increase the productivity are essential to reduce in a sustainable manner the unemployment rate. The improvement of the business climate would allow private firms to increase their productivity and thus strengthen their ability to create jobs. It should also alleviate the tax pressure on the activities that are labor-intensive.

On the one hand, employers claim more labor market flexibility. On the other hand, strong pressures are exerted by trade unions in order to claim the protection of employees, particularly the vulnerable groups - in order to preserve social cohesion and stability. A fair balance between efficiency and equity is necessary in order to provide a new social contract.

\section{References}

Avdagic Sabina, Salardi Paola (2013), "Tenuous link: labour market institutions and unemployment in advanced and new market economies", Socio-Economic Review, Vol. 11, pp. 739-769.

Bassanini, A., R. Duval, (2009), "Unemployment, Institutions, and Reform Complementarities: Reassessing the Aggregate Evidence for OECD Countries," Oxford Review of Economic Policy, Vol. 25, No. 1, pp. 40-59. 
Berg Janine et Sandrine Cazes (2007) «Les Indicateurs Doing Business : Limites méthodologiques et conséquences politiques «Cahiers de l'économie et du marché du travail 2007/9 ILO.

Bernal-Verdugo, L., D. Furceri, and D. Guillaume, (2012), "Labor Market Flexibility and Unemployment: New Empirical Evidence of Static and Dynamics Effects," IMF Working Papers 1264, Washington, IMF.

Blanchard Olivier, Wolfers Justin (2000) "The role of shocks and institutions in the rise of UE unemployment the aggregate evidence", The Economic Journal $n^{\circ} 110$.

Botero, Juan C., et al., (2004), "The Regulation of Labor" Quarterly Journal of Economics, Vol. 119 (4), 1339-82.

Baker, D., Glyn, A., Howell, D. and Schmitt, J. (2005) 'Labour Market Institutions and Unemployment: A Critical Assessment of the Cross-Country Evidence'. In Howell, D. (ed.) Fighting Unemployment. The Limits for Free Market Orthodoxy, Oxford, pp. 72118.

Deakin Simon Prabirjit Sarkar (2015) "Labour law increase youth and total unemployment? Analysis of a new dataset for 31 countries", 19th Annual Conference of The International Society for New Institutional Economics (Harvard Law School. Cambridge, Massachusetts, USA June $18-20$.

Djankov Simeon, Rita Ramalho (2009) "Employment laws in developing countries", Journal of Comparative Economics, vol. 37, pp. 3-13.

Feldmann, Horst (2009) "The Unemployment Effects of Labor Regulation Around the World," Journal of Comparative Economics Vol. 37, 1: 76-90.

Howell, D., D. Baker, A. Glynn, J. Schmitt (2006) “Are Protective Labor Market Institutions Really at the Root of Unemployment? A Critical Perspective on the Statistical Evidence".

Koranchelian, Taline Domenico Fanizza (2005) «How Does Employment Protection Legislation Affect Unemployment in Tunisia? A Search Equilibrium Approach», IMF, $\mathrm{WP} / 05 / 92$.

\section{Annexes}

->Tunisia

\begin{tabular}{|c|c|c|c|c|c|}
\hline Variable | & Obs & Mean & Std. Dev. & Min & Max \\
\hline imf_ue | & 13 & 14.39923 & 1.94794 & 12.397 & 18.3 \\
\hline wdi_une yilo | & 13 & 29.43077 & 1.79415 & 27 & 32.4 \\
\hline wdi_unempilo| & 13 & 13.59231 & 1.17647 & 12.4 & 15.7 \\
\hline imf_gdpgr| & 13 & 3.87684 & 2.18710 & -1.937 & 6.2 \\
\hline hirin & 12 & 7.394443 & 32 & 0.1 & 8.33333 \\
\hline hiringfiri $\sim \mathrm{g}$ & 13 & 5.071935 & .5148315 & 4.10864 & 5.83333 \\
\hline centcolbar $\sim \mathrm{g}$ & 13 & 4.978615 & .8981367 & 3.15789 & 6.13534 \\
\hline hoursreg | & 12 & 9.241667 & .6694073 & 8.7 & 10 \\
\hline mandcostdi $\sim 1 \mid$ & 12 & 8.231956 & .3673267 & 7.75518 & 8.79482 \\
\hline labore & 13 & 6.145941 & .7557364 & 3.7698 & 6.80162 \\
\hline
\end{tabular}


-> Other countries

\begin{tabular}{|c|c|c|c|c|c|}
\hline Variable | & Obs & Mean & Std. Dev. & Min & Max \\
\hline imf_ue | & 919 & 9.901319 & 6.29403 & .658 & 38.4 \\
\hline wdi_une yilo | & 1483 & 18.45745 & 12.20178 & .7 & 65.9 \\
\hline wdi_unempilo| & 1483 & 9.213082 & 6.75300 & .3 & 38.7 \\
\hline imf_gdpgr | & 1488 & 4.582652 & 4.28721 & -17.699 & 34.5 \\
\hline hiringregm- & 1386 & 6.197036 & 2.770038 & 0 & 10 \\
\hline hiringfiri g & 1261 & 4.753807 & 1.274146 & 0 & 8.80176 \\
\hline centcolbar $\sim \mathrm{g}$ & 1262 & 6.714013 & 1.241837 & 2 & 8.87681 \\
\hline hoursreg | & 1352 & 7.677518 & 1.849714 & 3.3 & 10 \\
\hline mandcostdi 1 | & 1263 & 5.614777 & 3.108114 & 0 & 10 \\
\hline laboreg & 1401 & 6.162641 & 1.409498 & 2.28 & 9.725 \\
\hline
\end{tabular}

